\title{
Angiotensin Converting Enzyme 2 in COVID-19 infections and the implications of COVID-19 on major body systems
}

\section{Malyn M.L.K Antoine ${ }^{1 *}$, Yancheng Xu', Rimanatou Seyni-Boureima², Chrystal D. Antoine-Frank ${ }^{3}$, Coumba Aicha Thiam ${ }^{4}$, MENDAME EHYA Regis Ernest ${ }^{5}$}

\author{
'Department of Endocrinology, Zhongnan Hospital of Wuhan University, Wuhan, Hubei, China \\ 2Department of Anaesthesiology, Zhongnan Hospital of Wuhan University, Wuhan, Hubei, China \\ ${ }^{3}$ Department of Anatomical Sciences, St. George's University, True Blue, Grand Anse, St. George, Grenada, West Indies \\ ${ }^{4}$ Department of Obstetrics and Gynaecology, Zhongnan Hospital of Wuhan University, Wuhan, Hubei, China \\ ${ }^{5}$ Department of Orthopaedic hand and microsurgery, Zhongnan Hospital of Wuhan Univeristy, Wuhan, Hubei, China
}

Keywords: Covid-19, coronavirus, SARS-CoV-2 virus, renin angiotensin system, angiotensin converting enzyme-2

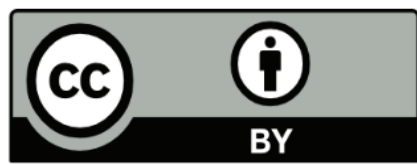

This work is licensed under a Creative Commons Attribution 4.0 Unported License.

\section{Abstract}

COVID-19, caused by the severe acute respiratory syndrome coronavirus (SARS-CoV-2), was first identified in China in late 2019 and since then, this disease has become a pandemic affecting many countries across the globe. Due to this outbreak, many researchers have been diligently investigating this disease for the establishment of better methods of its treatment and control. Evidence from research has led to a plethora of valuable but uncertain information on the modes of transmission of COVID-19 and the mechanisms by which SARS-CoV-2 establishes infections in targeted tissues. It is now better understood that in this disease, SARS-CoV-2 gains entrance into cells by specifically binding ACE-2 (angiotensin-converting enzyme 2); ACE-2 serves as a potential receptor for the virus. The lungs, in addition to many other organs and tissues, express ACE- 2 in varying degrees. Therefore, this review will examine the role of ACE-2 in COVID-19 and the secondary effects that COVID-19 has on organs that express ACE-2. To this end, it will assist in establishing the relationship between the ACE-2 receptor and SARS-CoV-2, bringing to the forefront the correlation between the symptomatology presentation, as well as the severity of infections experienced with COVID-19. Given this, it may even provide an avenue for the generation of treatment, or create a platform for the enhanced knowledge of this novel virus, and therefore, control, and maybe unravel the mystery for long term complications.

In addition to the lungs, it has been demonstrated that ACE2 is expressed in other parts of the body including the heart, brain, kidneys and blood vessels. Despite the fact that SARSCoV-2 mainly affects the lung, producing respiratory symptoms, since other tissues of the body also express ACE- 2 they are too susceptible, and serve potential targets for SARS-CoV-2. Therefore, this review aims at exploring ACE- 2 and SARS-CoV- 2 in addition to examining the effects that SARS-CoV-2 may have on major body systems.

\section{*Corresponding Author:}

Malyn M.L.K Antoine

Wuhan University, Medical Department,

Donghu Road, Wuchang District,

Wuhan City, Hubei Province, China

Email: Mackiki29@gmail.com 
Renin-Angiotensin System and Angiotensin Converting Enzyme 2

A major regulator of homeostasis and fluid balance in the body is the renin-angiotensin system (RAS). Ang II, the primary hormone resulting from the activation of this system, is generated by the initial cleavage of angiotensinogen (Agt) and the eventual production of Ang II. Through the binding of specific receptors, Ang II exhibits its effect on various organs in the body including the kidneys, brain, heart and blood vessels ${ }^{8}$.

Agt is described as an alpha2- globin which is mainly produced by the liver. Renin, a proteolytic enzyme, cleaves Agt subsequently producing angiotensin (Ang) I. Ang I, described as a decapeptide, is subsequently converted to Ang II (an octapeptide) primarily by angiotensin-converting enzyme (ACE). Ang II exhibits its effects through two $G$ protein- coupled receptors: 1) angiotensin type $1\left(\mathrm{AT}_{1}\right)$ receptors and 2 ) angiotensin type $2\left(\mathrm{AT}_{2}\right)$ receptors. In the kidneys, vasoconstriction of the afferent and efferent arterioles and the reabsorption of sodium and fluids are primarily mediated by Ang II activation of AT receptors. In addition, the release of aldosterone from the zona glomerulosa of the adrenal cortex is also achieved through Ang II stimulation of $\mathrm{AT}_{1}$ receptors ${ }^{9}$.

Ang II is cleaved by ACE-2 to produce Ang-(1-7). Ang (1-7) promotes vasodilation, limits inflammation and exhibits anti-fibrotic effects through its interactions with MAS, a G-protein coupled receptor ${ }^{10}$. Furthermore, ACE-2 converts Ang I into Ang-(1-9) and ACE then converts Ang (1-9) into Ang-(1-7). The activation of the RAS depends highly on the ratio of ACE/ACE-2 found in tissues as the effects of ACE are counteracted by ACE-2. The ratio of ACE/ACE2 determines the balance between pathways that promote or supress inflammation and fibrosis ${ }^{11}$.

Renin is considered the rate-limiting enzymatic step in the production of Ang II. In the kidneys, renin is synthesized by specialized cells found in the afferent arterioles called juxtaglomerular (JG) cells. It is then released into the vascular spaces and connective tissue within the kidneys. There are different factors that regulate the synthesis and release of renin. Its secretion is positively controlled by cyclic adenosine monophosphate (CAMP). Renin release is also influenced by factors that affect blood volume, extracellular fluid (ECF) volume and pressures within arterioles. Renin release may be regulated by: 1) baroreceptors found within the afferent arterioles of the kidneys, 2) changes in sodium chloride concentrations of the fluid delivered to cells of the macula densa and 3 ) influences of sympathetic innervations of arterioles of the JG apparatus?.

\section{Tissue Distribution of ACE-2}

ACE- 2 is expressed in the lung, small intestines and blood vessels. This protein can also be found in the kidneys, skin, oral and nasal cavities ${ }^{12}$. Since ACE- 2 is expressed in regions within the body that are commonly exposed to the external environment (respiratory and digestive tracts), potential routes are thus provided for the easy transmission of SARS-CoV-2 in exposed and susceptible individuals ${ }^{13}$.

\section{COVID-19 and Angiotensin Converting Enzyme 2}

As stated earlier SARS CoV-2 is the virus responsible for the development of the disease, COVID-19. This virus binds to tissue ACE-2, subsequently establishing an infection as evidence has already identify ACE-2 as a functional receptor for SARS-CoV ${ }^{14}$. As compared to SARS-CoV-1, SARS-CoV-2 exhibits a higher binding affinity (10-20 folds higher) for ACE-2 ${ }^{6,15}$ thus potentially increasing the transmission of and susceptibility to SARS-CoV-2 in the presence of an increased expression of ACE-2. In order for the corona virus to invade and infect target cells, it utilizes a spike glycoprotein which is contained in its viral envelop. This spike glycogen structure contains a receptor binding domain which interacts with subdomain I of ACE-2. Cell entry of the virus is then facilitated by priming of the serine protease TMPRSS2 ${ }^{16,17}$.

ACE-2 can be identified in different organs of the body. It is established that in the lungs, ACE-2 is mainly found on type II alveolar epithelial cells and even though it is also found in the mucosal layer of the oral cavity, nasal cavity and nasopharynx, it is only weakly expressed in these areas of the body ${ }^{12,18}$. Although evidence suggests that the lung is the main target site for SARSCoV-2 infections, it is also possible for other organs of the body, such as the heart, kidneys and gastrointestinal $(\mathrm{Gl})$ tract, to be affected by this virus as they also express ACE- 2 in varying degrees ${ }^{17}$.

\section{COVID-19 and the body systems}

As is previously established SARS-CoV-2 utilizes ACE-2 as a potential receptor to gain access into cells, subsequently establishing an infection. Although ACE-2 is present in the lungs, it is evident that other tissues of the body, including tissues of the small intestine, central nervous system and cardiovascular system, also express ACE-2. Therefore, in addition to exploring the effects of this disease on the lungs, it is also interesting and important to investigate the effects of COVID-19 on other systems of the body as this may give some insight into symptom presentation.

\section{Effects of COVID-19 on the respiratory system}

In the respiratory system, ACE-2 is found in the nose, bronchus and on the surface of type II pneumocytes ${ }^{19,20}$. Respiratory symptoms are described as some of the earliest symptoms of COVID-19 ${ }^{21}$. COVID-19 infections may be associated with acute respiratory distress syndrome ${ }^{22,23}$. The presence of an infection with SARS-CoV-2, induces a series of changes within the lungs and as the disease advances, pathological changes such as thickening of the alveolar septa may be observed. Inflammatory changes may also occur with the presence of mononuclear cells within the interstitium, and multi-nucleated giant cells within alveoli ${ }^{24,25}$.

The RAS functions in the lung to control vascular tone in addition to maintaining the integrity of the alveolar capillaries and regulating inflammatory responses. Both the ACE/Ang II and ACE2/Ang-(1-7) pathways are present in different cells of the lung; however, the ACE/Ang II pathway predominates. Insults and injuries to the lung result in the up-regulation and stimulation ACE/Ang II and the suppression of ACE-2/Ang-(1-7), thus resulting in further injury. It is believed that the presence of SARS-CoV-2 promotes an increased expression of the ACE/Ang II pathway, as it causes a down regulation of ACE- 2 expression ${ }^{26}$. This effect, causes a subsequent increase in Ang II concentrations in the lung and it also increases AT, receptor activities thus resulting in lung injury ${ }^{27}$.

Within the lung, the function of the ACE/Ang-(1-7)/Mas pathway may confer some protective effects. This axis aids in decreasing inflammation as well as preventing fibrosis and reducing pressures within pulmonary arteries. A study carried out on animals which involved the infusion of Ang-(1-7), demonstrated the following effects within the lungs: 1 ) decreased resistance and edema within pulmonary vessels, 2 ) increased partial pressure $(\mathrm{PaO} 2)$ of oxygen within the lungs, 3 ) inhibition of tumour necrotic factor a (TNFa) 
activities, 4) increased ratio of $A C E-2 / A C E$, 5) increased ratio of Ang-(1-7)/Ang II, and 6) reduced inflammation ${ }^{28}$.

\section{Effects of COVID-19 on the nervous system}

ACE-2 is expressed in different regions of the brain including the cerebral blood vessels, choroid plexus and neurons of the neocortex ${ }^{12,29}$. In the central nervous system (CNS) ACE-2 is also expressed in regions of the brainstem ${ }^{30}$. Therefore, invasion and infection of the CNS by SARS-CoV-2 is quite possible. COVID-19 patients may present with symptoms of ageusia and anosmia 31,32. Many patients also report other neurological symptoms such as headaches and mental confusion ${ }^{33,34}$.

Different routes have been theorized to explain the entrance of this virus into the nervous system. One of the potential routes considered is through invasion of the olfactory bulb. An animal study investigating aspects of SARS-CoV infection of the brain demonstrated that SARSCoV-1 initially infected the olfactory bulb, subsequently spreading transneurally ${ }^{35}$. The SARS-CoV-2 virus may potentially utilize a similar route to enter the CNS. Entrance through the blood brain barrier (BBB) has also been considered. ACE-2 is found within the cerebral vasculature, therefore endothelial damage may potentially occur through the interactions of ACE- 2 with SARS-CoV-2 thus resulting in a breach in the BBB subsequently allowing viral entrance into the $\mathrm{CNS}^{36,37}$. The breach in the BBB commonly follows inflammation due to the release of inflammatory mediators such as interleukin 6, interleukin 8 and monocyte chemoattractant protein-1 (MCP-1) by immune cells triggered by the presence of the virus ${ }^{38,39}$. Infected immune cells such as monocytes and T-cells may also serve as potential carriers of the SARS-CoV-2 virus into the CNS as these cells can potentially infiltrate the cerebral blood vessels, meninges and choroid plexus ${ }^{40}$. In patients diagnosed with COVID-19, evidence has already demonstrated the nucleocapsid protein of SARS-CoV-2 in CD68+ immune cells and the RNA of SARS-CoV-2 in macrophages obtained from bronchoalveolar lavage ${ }^{41,42}$. However, further research is needed to exactly determine the interactions between the SARS-CoV-2 virus and immune cells as evidence from autopsy investigations have failed to significantly demonstrate a direct invasion of immune cells by this virus ${ }^{43,44}$.

It is also postulated that the neurological manifestations in COVID-19 may be caused indirectly by the effects of the virus on the respiratory system. As the virus invades and destroys lunch tissue, hypoxemia occurs due to pure blood oxygenation. Hypoxemia can then lead to hypoxia within the brain, thus resulting in neurological symptoms such as altered levels of consciousness, coma or even death ${ }^{45}$.

\section{Effects of COVID-19 on cardiovascular system}

ACE2 is expressed in the heart, thus rendering this organ quite susceptible to SARS-CoV-2 infections ${ }^{46}$. Acute myocardial injury is very common in patients suffering from COVID-19 and it has been observed that this complication in COVID-19 patients is associated with an increased risk of mortality (7-11 fold increase in mortality rates $)^{47}$. One study carried out to assess the incidence and significance of cardiac injury in patients with COVID-19 reported that cardiac injury was observed in $19.7 \%$ of patients that were hospitalized with this disease. This study also identified the presence of cardiac injury as an independent risk factor for determining mortality in patients that are hospitalized with COVID-1948.

The exact mechanism by which the presence of SARSCoV-2 induces this complication is not well understood; however, different factors have been proposed in an attempt to explain this pathology. Cardiac damage may occur as the SARS-CoV-2 virus directly invades and replicates within cardiac cells causing viral induced myocarditis. In addition, cytokines released in response to the presence of SARS-CoV-2, may induce systematic inflammation which may also lead to cardiomyopathy or cardiac injury ${ }^{49,50}$. In the heart, ACE-2/Ang-(1-7)/Mas pathway may exhibit positive effects through promoting vasodilation and relaxation of cardiac vessels, reducing oxidative stress and enhancing cardiac function after an ischemic insult ${ }^{51,52}$. Studies utilizing both human and animal subjects demonstrate that the presence of SARS-CoV-1 infection induces a reduction in ACE-2 expression in myocardial cells ${ }^{53}$. In COVID-19, the increased levels of Ang II following a downregulation of ACE-2 expression, causes an over stimulation of the RAS. The protective effects of the ACE-2/ Ang-(1-7)/Mas pathway is reduced and cardiac injury may therefore be promoted ${ }^{17}$.

ACE-2 can be found in the endothelium of blood vessels. It has been demonstrated that SARS-CoV-2 can potentially cause inflammation in the endothelium of blood vessels by directly infecting endothelial cells ${ }^{54}$. The SARS RNA has been isolated from the cells lining small veins of various tissues in the body ${ }^{55}$. The endothelium has the potential to produce Ang-(1-7) and within blood vessels, the ACE-2/ Ang-(1-7)/Mas pathway promotes vasodilation and also enhances anti-thrombotic effects ${ }^{51,12}$. The plasma levels of D-dimer are significantly increased in severe cases of COVID-19 and severely ill patients commonly suffer from disseminated intravascular coagulation $(\mathrm{DIC})^{56,57,34}$. D-dimers are present in the blood following fibrinolysis, a process which degrades blood clots. DIC in COVID-19 patients may occur due to the development of thrombosis in both veins and arteries. Thrombosis in arteries may lead to cerebrovascular accidents, myocardial infarctions and peripheral ischaemia ${ }^{58,59}$. One study carried out to determine the incidence of thrombotic complications in critically ill intensive care unit (ICU) patients with COVID-19, demonstrated a $27 \%$ incidence of venous thromboembolism (VTE) and 3.7\% incidence of arterial thrombosis. This study also reported pulmonary embolism (PE) (80\%) as the most frequently observed thrombotic complication ${ }^{60}$. In addition, through the observation of autopsies, thrombi have also been demonstrated within the pulmonary vasculature ${ }^{61}$.

\section{Effects on the endocrine and reproductive system}

The endocrine system which consists of a series of organs is also affected by the SARS-CoV-2 virus. It is not yet fully understood how this virus gains entry into the CNS; however, the presence of the SARS-CoV-1 genome has already been demonstrated within the hypothalamus and one study has already shown that both the hypothalamus and pituitary gland are affected by SARS-CoV-1 ${ }^{62,63}$. It might be safe to assume that similarly to SARS-CoV-1, SARSCoV-2 may also have some damaging effects on the hypothalamus and pituitary gland ${ }^{63}$. The SARS-CoV-1 virus, potentially exhibit similar amino acid sequences to the adrenocorticotropic hormone (ACTH), a hormone secreted in the blood from the pituitary gland. The presence of viral particles in the blood that share similar structure to ACTH, results in the destruction of ACTH by antibodies that were initially formed against these viral particles. This leads to adrenal insufficiency ${ }^{64}$. Since the proteins of SARS-CoV-1 and SARS-CoV-2 are quite similar, it is possible the SARSCoV-2 may utilize a similar mechanism in disrupting the hypothalamicpituitary-adrenal axis ${ }^{65}$. With the involvement of this axis, blood cortisol levels may be severely lowered following an infection with SARS-CoV-2 virus; therefore causing psychological effects and tiredness. 
Serum levels of free T3,T4 and TSH have been shown to be reduced in patients infected with SARS-CoV- $1^{66}$. This may be attributed to the development of sick-euthyroid syndrome or central hypothyroidism. Illnesses such as COVID-19 infections can disrupt the thyroid axis decreasing the blood levels of T4 and TSH. During a period of illness, like with SARS-CoV- 2 infection, the tissue binding and uptake of thyroid hormones may be disrupted. In addition, hormones such as cortisol and inflammatory mediators like cytokines may interrupt the normal function of type I deiodinase, limiting the conversion of T4 to T3 thus reducing T3 levels. Furthermore, T3 levels may be further reduced due to the increased activity of type 3 deiodinase ${ }^{67}$. In addition to the mechanisms already outlined, thyroid hormone levels during COVID-19 illness, even though not yet demonstrated, may possibly be affected by the direct damaging effects of the SARS-CoV-2 virus on this organ. An autopsy study on 5 SARS patients reported significant destruction of the thyroid follicular and para-follicular cells by SARS-CoV-1. Destruction of the thyroid parenchyma causes decreased T3 and T4 levels while damaged para-follicular cells affects the blood levels of calcitonin ${ }^{68}$. To date, much data has not yet been accumulated regarding the thyroid involvement in COVID-19; however, COVID-19 patients who present with a pre-existing history of thyroid diseases should continue medical treatment. Patients taking medications for hyperthyroidism should be closely monitored as they are at an increased risk for developing complications such as agranulocytosis ${ }^{63}$.

Both the endocrine and exocrine pancreas express ACE-2 and damage to the exocrine pancreas can result in elevated levels of amylase and lipase ${ }^{69}$. When the endocrine pancreas becomes involved, abnormal glucose metabolism is observed. A study which assessed 39 SARS-CoV-1 patients with no history of diabetes and no use of steroids showed significant increase in fasting plasma glucose as compared to their matched healthy siblings. During the follow up period, 20 patients were identified as having diabetes upon hospitalization and following a 3 year follow-up period, diabetes persisted in 2 patients. This study also concluded that through the use of ACE-2 expressed on pancreatic islet cells, SARS coronavirus enters and damages islet cells resulting in acute diabetes ${ }^{70}$. SARS coronavirus induces an increase in fetuin A levels. Fetuin $A$ is a glycoprotein that has been shown to be associated with abnormal insulin sensitivity; therefore, COVID-19 patients presenting with a previous history of type-2 diabetes mellitus (T2DM), may experience worsening of their insulin resistance due to increased levels of this glycoprotein ${ }^{71}$.

Despite the availability of information regarding testicular involvement in COVID-19, there remains a deficiency of information regarding ovarian involvement in this disease ${ }^{63}$. ACE-2 is expressed in the testes and can be found on leydig and sertoli cells in addition to the spermatogonia. The blood testosterone levels may be altered in men suffering from SARSCoV-2 infections. A study carried out comparing 81 males of reproductive aged diagnosed with SARS-CoV-2 infection to 100 healthy males, reported that the male subjects presenting with COVID-19 showed an increase in their serum levels of luteinizing hormone (LH); however, the ratios of testosterone to $\mathrm{LH}$ and follicle stimulating hormone (FSH) to $\mathrm{LH}$ were both significantly reduced. Even though inflammation caused by covid-19 infections may result in abnormal stimulations from the hypothalamus or pituitary gland ${ }^{72}$, the findings from this study may support the notion that in COVID-19, disturbances in the male reproductive hormone levels may be more due to abnormalities at the level of the testes.

REffects of COVID-19 on the gastrointestinal system
SARS-CoV-2 RNA has already been identified from stool specimens ${ }^{73}$. Patients diagnosed with COVID-19 commonly presents with diarrhoea. Other gastrointestinal symptoms commonly observed include nausea, vomiting, anorexia and abdominal pain $^{74,75}$. One study was carried out in China to investigate the clinical characteristics of patients presenting with COVID-19. This study which enrolled 1099 patients, from 552 hospitals, across 30 different provinces demonstrated that $3.8 \%$ of patients presented with diarrhoea and $5.6 \%$ of patients presented with nausea or vomiting or both nausea and vomiting ${ }^{76}$. Diarrhoea may occur alone in the absence of respiratory symptoms. One study carried out to assess the clinical, pathologic, and virologic features of the intestinal involvement of the SARS-CoV-2 virus reported that watery diarrhoea was the most common gastrointestinal symptom observed and it was present in $20.3 \%$ of study subject while fever and diarrhoea with an absence of respiratory symptoms were reported in $5.8 \%$ of study participants who presented with COVID-19 ${ }^{77}$. It is postulated that the prognosis for COVID-19 infections can be predicted based on the presence or absence of gastrointestinal symptoms ${ }^{78}$; however, more research in this regards is required as evidence from difference sources yields contradictory results ${ }^{76,79,80}$.

Different mechanisms have been postulated to explain the development of gastrointestinal symptoms in COVID-19 patients. In the digestive tract SARS-CoV-2 can potentially interact with ACE2 causing diarrhoea. Evidence has already been brought forward to support the presence of ACE- 2 in the linings of the oesophagus, and the absorptive cells of small and large intestines ${ }^{81}$. The presence of ACE-2 in different regions of the digestive tract increases the likelihood that the SARS-CoV-2 virus may establish infections in this region of the body by directly binding to ACE-2, thus gaining entrance into intestinal cells. This may be followed by the development of diarrhoea as viral cellular invasion and subsequent infection may cause imbalances in intestinal secretions, impair absorption from the gastrointestinal tract and potentially activate the enteric nervous system (ENS). In addition, infection with COVID-19 also stimulates inflammatory responses that may lead to inflammatory induced damage to intestinal cells, thus resulting in diarrhoea ${ }^{82}$. It is also theorized that when infected with the SARS-CoV-2 virus, diarrhoea may occur secondary to the use of antibiotics/antiretroviral drugs or due to the viral disruption of the normal flora of the gastrointestinal tract ${ }^{83,84}$. It is also important to note that the COVID-19 infections alter the normal function of ACE-2. ACE-2 regulates homeostasis within the gut; therefore, the disruption of the normal function of ACE-2 makes the gastrointestinal tract more vulnerable to the effects of inflammation thus contributing to the development of gastrointestinal symptoms including diarrhoea ${ }^{85,86}$.

The laboratory results of a patient suffering from COVID-19 may reveal elevated levels of aspartate aminotransferase (AST), alanine transaminase (ALT), Gamma Glutamyl Transferase $(\gamma-$ GT), and Alkaline phosphatase (ALP). Patients may also present with hypoalbuminaemia and increased clotting time ${ }^{87}$. Different mechanisms for the cause of liver injury in COVID-19 have been theorized since the exact mechanism of injury is not yet known. It has been demonstrate that within the liver ACE-2 is mainly expressed on cholangiocytes ${ }^{88}$. Therefore, the presence of ACE2 serve as a potential receptor for the direct binding of SARSCoV- 2 within the hepatic system, thus inducing cellular damage ${ }^{89}$. Evidence also suggests that damages within the hepatic system by SARS-CoV-2 infections may be due to inflammatory responses caused by the presence of the viral infection ${ }^{90}$. The use of high dose anti-viral drugs in addition to the use of antibiotics, antipyretics and steroids should also be investigated as potential causes of hepatic damage in patients suffering from COVID-19 ${ }^{87,91}$. 


\section{Effects of COVID-19 on the renal system}

ACE-2 has been identified in different regions of the kidneys therefore, this demonstrates a susceptibility of this organ to infections with SARS-CoV-2 $2^{20,92}$. The presence of proteinuria and increased levels of creatinine and blood urea nitrogen have already been observed in patients diagnosed with COVID-1993. In addition, patients suffering from SARS-CoV-2 infections are also at an increased risk for developing acute kidney injury $(A K I)^{67}$. A study designed to investigate the occurrence of AKI in hospitalized COVID-19 patients demonstrated that AKI occurred in 1,993 (36.6\%) study participants out of a total of 5499 subjects $^{94}$. The exact mechanism by which the SARS-CoV-2 virus induces renal injury is not yet well understood; however, since ACE-2 is highly expressed in the kidneys, it is possible that injury may follow the binding and entrance of the virus into cells subsequently establishing an infection with eventually causing tissue damage ${ }^{95}$. Evidence from post-mortem discoveries demonstrates the presence of diffuse acute tubular injury (ATI), in addition to necrosis and damage to the brush border of the proximal renal tubules ${ }^{96}$. Therefore, it is evident that the effects of the SARS-CoV-2 virus damages the renal parenchyma, particularly affecting the renal tubular epithelium, with secondary endothelial involvement ${ }^{97}$. It is also theorized that during an infection with SARS-CoV-2, renal injury may follow the deposition of immune complexes within the kidneys. In addition, it is believed that the presence of viral particles or antigen within the kidneys may induce the excess release of cytokines which potentially causes inflammation and subsequent tissue damage $\mathrm{e}^{98,99}$.

\section{Future direction and conclusion}

Since the outbreak of COVID-19 in 2019, much research has been carried out, as means of developing effective methods for treating the disease and controlling its spread. To date, although much information has already been accumulated on COVID-19, this disease still place a great burden on healthcare facilities as the number of cases continue to rise in different countries around the world. Discoveries made on the mode of infection of the SARSCoV-2 virus, have led to a promising future for the management and control of COVID-19. Evidence suggests that SARS-CoV-2 establishes an infection by binding to targeted cells that express ACE- $2^{5,6}$. In addition to the lungs, various organs and tissues of the body also express ACE- 2 and are therefore susceptible to SARSCoV-2 infections ${ }^{12}$. This knowledge aids physician's understanding on the clinical presentation of COVID-19 patients. Knowledge accumulation can also facilitate better understanding on the modes of transmission of SARS-CoV-2 as the RNA of this virus has already been isolated from stool samples and can therefore suggest an oral-faecal mode of transmission ${ }^{100}$.

Knowledge on the use of ACE-2 by SARS-CoV-2 as means of entering and infecting target cells has also raised interest in investigating effective methods for managing COVID-19. ACE2 levels may be increased by the use of ACE inhibitors and angiotensin receptor blockers (ARBs) ${ }^{100}$. ACE-2 has protective effects on lung tissues as it decreases inflammatory effects by decreasing Ang II and increasing ang-(1-7) 101,7. The inhibition of Ang II formation by ACE inhibitors or the blockade of AT1 receptors by $A R B s$ also potentially decreases inflammation in the renal and cardiovascular systems and may therefore function to alleviate some of the major complications observed in COVID-19 patients ${ }^{102,103}$.

In conclusion, it is evident that SARS-CoV-2 establishes an infection by binding to ACE-2 expressed on target organs and tissues. Various regions of the body apart from the lung express
ACE-2 and this therefore explains the common symptoms and complications that may accompany an infection with SAR-CoV-2.

\section{Declaration of interest}

The authors of this paper declare no conflict of interests.

\section{References}

1. Gheblawi Mahmoud, Wang Kaiming, Viveiros Anissa, et al. Angiotensin-Converting Enzyme 2: SARS-CoV-2 Receptor and Regulator of the Renin-Angiotensin System. Circulation Research. 2020 May 8;126(10):1456-74.

2. Coronavirus Update (Live): 23,283,313 Cases and 806,231 Deaths from COVID-19 Virus Pandemic - Worldometer [Internet]. [cited 2020 Aug 23]. Available from: https://www. worldometers.info/coronavirus/

3. Patel Vaibhav B., Zhong Jiu-Chang, Grant Maria B., et al. Role of the ACE2/Angiotensin 1-7 Axis of the ReninAngiotensin System in Heart Failure. Circulation Research. 2016 Apr 15;118(8):1313-26.

4. Wang K, Gheblawi M, Oudit GY. Angiotensin Converting Enzyme 2: A Double-Edged Sword. Circulation. 2020 Mar 26;

5. Wan Y, Shang J, Graham R, et al. Receptor Recognition by the Novel Coronavirus from Wuhan: an Analysis Based on DecadeLong Structural Studies of SARS Coronavirus. Journal of Virology [Internet]. 2020 Mar 17 [cited 2020 Aug 23];94(7). Available from: https://jvi.asm.org/content/94/7/e00127-20

$6 . \quad H o f f m a n n$ M, Kleine-Weber $\mathrm{H}$, Schroeder S, et al. SARSCoV-2 Cell Entry Depends on ACE2 and TMPRSS2 and Is Blocked by a Clinically Proven Protease Inhibitor. Cell. 2020 Apr 16;181(2):271280.e8.

7. Schiffrin EL, Flack JM, Ito $S$, et al. Hypertension and COVID-19. Am J Hypertens. 2020 Apr 29;33(5):373-4.

8. Sparks MA, Crowley SD, Gurley SB, et al. Classical ReninAngiotensin System in Kidney Physiology. Compr Physiol. 2014 Jul;4(3):1201-28.

9. Harrison-Bernard LM. The renal renin-angiotensin system. Advances in Physiology Education. 2009 Dec 1;33(4):2704.

10. Sanchis-Gomar F, Lavie CJ, Perez-Quilis C, et al. Angiotensin-Converting Enzyme 2 and Antihypertensives (Angiotensin Receptor Blockers and Angiotensin-Converting Enzyme Inhibitors) in Coronavirus Disease 2019. Mayo Clin Proc. 2020 Jun;95(6):1222-30.

11. Hamming I, Cooper ME, Haagmans BL, et al. The emerging role of ACE2 in physiology and disease. The Journal of Pathology. 2007 May;212(1):1.

12. Hamming I, Timens $W$, Bulthuis $M$, et al. Tissue distribution of ACE2 protein, the functional receptor for SARS coronavirus. A first step in understanding SARS pathogenesis. J Pathol. 2004 Jun;203(2):631-7.

13. Xu H, Zhong L, Deng J, et al. High expression of ACE2 receptor of 2019-nCoV on the epithelial cells of oral mucosa. International Journal of Oral Science. 2020 Feb 24;12(1):1-5.

14. LiW, Moore MJ, Vasilieva N, et al. Angiotensin-converting enzyme 2 is a functional receptor for the SARS coronavirus. Nature. 2003 Nov;426(6965):450-4. 
15. Wrapp D, Wang N, Corbett KS, et al. Cryo-EM structure of the 2019-nCoV spike in the prefusion conformation. Science. 2020 13;367(6483):1260-3.

16. Matsuyama S, Nagata N, Shirato K, et al. Efficient Activation of the Severe Acute Respiratory Syndrome Coronavirus Spike Protein by the Transmembrane Protease TMPRSS2. Journal of Virology. 2010 Dec;84(24):12658.

17. Ni W, Yang $X$, Yang $D$, et al. Role of angiotensinconverting enzyme 2 (ACE2) in COVID-19. Critical Care. 2020 Jul 13;24(1):422.

18. Zou X, Chen K, Zou J, et al. Single-cell RNA-seq data analysis on the receptor ACE2 expression reveals the potential risk of different human organs vulnerable to 2019-nCoV infection. Front Med. 2020 Apr 1;14(2):185-92.

19. Zhao Y, Zhao Z, Wang Y, et al. Single-cell RNA expression profiling of ACE2, the putative receptor of Wuhan 2019-nCov. bioRxiv. 2020 Jan 26;2020.01.26.919985.

20. Meng $\mathrm{T}$, $\mathrm{Cao} \mathrm{H}$, Zhang $\mathrm{H}$, et al. The insert sequence in SARS-CoV-2 enhances spike protein cleavage by TMPRSS. bioRxiv. 2020 Feb 16;2020.02.08.926006.

21. Chen Q, Quan B, Li X, et al. A report of clinical diagnosis and treatment of nine cases of coronavirus disease 2019. Journal of Medical Virology. 2020;92(6):683-7.

22. Wu F, Zhao S, Yu B, et al. A new coronavirus associated with human respiratory disease in China. Nature. 2020 Mar;579(7798):265-9.

23. Zhou P, Yang X-L, Wang X-G, et al. A pneumonia outbreak associated with a new coronavirus of probable bat origin. Nature. 2020 Mar;579(7798):270-3.

24. Wichmann $D$, Sperhake J-P, Lütgehetmann $M$, et al. Autopsy Findings and Venous Thromboembolism in Patients With COVID-19. Ann Intern Med [Internet]. 2020 May 6 [cited 2020 Aug 30]; Available from: https://www.ncbi.nlm.nih.gov/pmc/articles/ PMC7240772/

25. $\quad \mathrm{Xu} \mathrm{Z}$, Shi $L$, Wang $Y$, et al. Pathological findings of COVID-19 associated with acute respiratory distress syndrome. Lancet Respir Med. 2020;8(4):420-2.

26. Edmonston DL, South AM, Sparks MA, et al. Coronavirus Disease 2019 and Hypertension: The Role of AngiotensinConverting Enzyme 2 and the Renin-Angiotensin System. Advances in Chronic Kidney Disease [Internet]. 2020 Jul 4 [cited 2020 Aug 30]; Available from: http://www.sciencedirect.com/ science/article/pii/S1548559520301129

27. Kuba K, Imai Y, Rao $S$, et al. A crucial role of angiotensin converting enzyme 2 (ACE2) in SARS coronavirus-induced lung injury. Nature Medicine. 2005 Aug;11(8):875-9.

28. Wösten-van Asperen RM, Lutter R, Specht PA, et al. Acute respiratory distress syndrome leads to reduced ratio of ACE/ACE2 activities and is prevented by angiotensin-(1-7) or an angiotensin II receptor antagonist. J Pathol. 2011 Dec;225(4):618-27.

29. Chen R, Wang K, Yu J, et al. The spatial and cell-type distribution of SARS-CoV-2 receptor ACE2 in human and mouse brain. bioRxiv. 2020 May 19;2020.04.07.030650.

30. Steardo L, Steardo L, Zorec R, et al. Neuroinfection may contribute to pathophysiology and clinical manifestations of COVID-19. Acta Physiol (Oxf). 2020;229(3):e13473.

31. Luers JC, Rokohl AC, Loreck N, et al. Olfactory and
Gustatory Dysfunction in Coronavirus Disease 19 (COVID-19). Clin Infect Dis. 2020 May 1;

32. Lechien JR, Chiesa-Estomba CM, De Siati DR, et al. Olfactory and gustatory dysfunctions as a clinical presentation of mild-to-moderate forms of the coronavirus disease (COVID-19): a multicenter European study. Eur Arch Otorhinolaryngol. 2020 Aug;277(8):2251-61.

33. Mao L, Jin $\mathrm{H}$, Wang $M$, et al. Neurologic Manifestations of Hospitalized Patients With Coronavirus Disease 2019 in Wuhan, China. JAMA Neurol. 2020 Jun 1;77(6):683-90.

34. Chen N, Zhou M, Dong $X$, et al. Epidemiological and clinical characteristics of 99 cases of 2019 novel coronavirus pneumonia in Wuhan, China: a descriptive study. The Lancet. 2020 Feb 15;395(10223):507-13.

35. Netland J, Meyerholz DK, Moore S, et al. Severe Acute Respiratory Syndrome Coronavirus Infection Causes Neuronal Death in the Absence of Encephalitis in Mice Transgenic for Human ACE2. Journal of Virology. 2008 Aug 1;82(15):7264-75.

36. Conde Cardona G, Quintana Pájaro LD, Quintero Marzola ID, et al. Neurotropism of SARS-CoV 2: Mechanisms and manifestations. J Neurol Sci. 2020 May 15;412:116824.

37. Sharifi-Razavi A, Karimi N, Rouhani N. COVID-19 and intracerebral haemorrhage: causative or coincidental? New Microbes and New Infections. 2020 May 1;35:100669.

38. Bell MD, Taub DD, Perry VH. Overriding the brain's intrinsic resistance to leukocyte recruitment with intraparenchymal injections of recombinant chemokines. Neuroscience. 1996 Sep;74(1):283-92.

39. Kaplanski G, Teysseire N, Farnarier C, et al. IL-6 and IL-8 production from cultured human endothelial cells stimulated by infection with Rickettsia conorii via a cell-associated IL-1 alphadependent pathway. J Clin Invest. 1995 Dec;96(6):2839-44.

40. Engelhardt B, Vajkoczy P, Weller RO. The movers and shapers in immune privilege of the CNS. Nature Immunology. 2017 Feb;18(2):123-31.

41. Chen Y, Feng Z, Diao B, et al. The Novel Severe Acute Respiratory Syndrome Coronavirus 2 (SARS-CoV-2) Directly Decimates Human Spleens and Lymph Nodes. medRxiv. 2020 Mar 31;2020.03.27.20045427.

42. Bost P, Giladi A, Liu Y, et al. Host-Viral Infection Maps Reveal Signatures of Severe COVID-19 Patients. Cell. 2020 Jun 25;181(7):1475-1488.e12.

43. Solomon $\mathbf{I H}$, Normandin E, Bhattacharyya $\mathrm{S}$, et al. Neuropathological Features of Covid-19. New England Journal of Medicine. 2020 Sep 3;383(10):989-92.

44. Kantonen J, Mahzabin S, Mäyränpää Ml, et al. Neuropathologic features of four autopsied COVID-19 patients. Brain Pathology [Internet]. [cited 2020 Oct 29];n/a(n/a). Available from: https://www.onlinelibrary.wiley.com/doi/abs/10.1111/ bpa.12889

45. Abdennour $L$, Zeghal $C$, Dème $M$, et al. [Interaction brain-lungs]. Ann Fr Anesth Reanim. 2012 Jun;31(6):e101-107.

46. Chen $L$, Li X, Chen $M$, et al. The ACE2 expression in human heart indicates new potential mechanism of heart injury among patients infected with SARS-CoV-2. Cardiovasc Res. 2020 01;116(6):1097-100.

47. Ni W, Yang X, Liu J, et al. Acute Myocardial Injury 
at Hospital Admission Is Associated With All-Cause Mortality in COVID-19. J Am Coll Cardiol. 2020 Jul 7;76(1):124-5.

48. Shi S, Qin M, Shen B, et al. Association of Cardiac Injury With Mortality in Hospitalized Patients With COVID-19 in Wuhan, China. JAMA Cardiol. 2020 Jul;5(7):802-10.

49. Hendren Nicholas S., Drazner Mark H., Bozkurt Biykem, et al. Description and Proposed Management of the Acute COVID-19 Cardiovascular Syndrome. Circulation. 2020 Jun 9;141(23):190314.

50. Madjid M, Safavi-Naeini P, Solomon SD, et al. Potential Effects of Coronaviruses on the Cardiovascular System: A Review. JAMA Cardiol. 2020 Jul 1;5(7):831-40.

51. Santos RAS, Sampaio WO, Alzamora AC, et al. The ACE2/ Angiotensin-(1-7)/MAS Axis of the Renin-Angiotensin System: Focus on Angiotensin-(1-7). Physiol Rev. 2018 Jan 1;98(1):505-53.

52. Jiang $F$, Yang J, Zhang $Y$, et al. Angiotensin-converting enzyme 2 and angiotensin 1-7: novel therapeutic targets. Nat Rev Cardiol. 2014 Jul;11(7):413-26.

53. Oudit GY, Kassiri Z, Jiang C, et al. SARS-coronavirus modulation of myocardial ACE2 expression and inflammation in patients with SARS. Eur J Clin Invest. 2009 Jul;39(7):618-25.

54. Varga Z, Flammer AJ, Steiger P, et al. Endothelial cell infection and endotheliitis in COVID-19. The Lancet. 2020 May 2;395(10234):1417-8.

55. Ql Z, Yq D, Jl H, et al. [Detection of severe acute respiratory syndrome (SARS)-associated coronavirus RNA in autopsy tissues with in situ hybridization]. Di Yi Jun Yi Da Xue Xue Bao. 2003 Nov 1;23(11):1125-7.

56. Huang C, Wang Y, Li X, et al. Clinical features of patients infected with 2019 novel coronavirus in Wuhan, China. The Lancet. 2020 Feb 15;395(10223):497-506.

57. Yang X, Yu Y, Xu J, et al. Clinical course and outcomes of critically ill patients with SARS-CoV-2 pneumonia in Wuhan, China: a single-centered, retrospective, observational study. The Lancet Respiratory Medicine. 2020 May 1;8(5):475-81.

58. Tang N, Li D, Wang $X$, et al. Abnormal coagulation parameters are associated with poor prognosis in patients with novel coronavirus pneumonia. Journal of Thrombosis and Haemostasis. 2020;18(4):844-7.

59. Bonow RO, Fonarow GC, O'Gara PT, et al. Association of Coronavirus Disease 2019 (COVID-19) With Myocardial Injury and Mortality. JAMA Cardiol. 2020 Jul 1;5(7):751-3.

60. Klok FA, Kruip MJHA, van der Meer NJM, et al. Incidence of thrombotic complications in critically ill ICU patients with COVID-19. Thromb Res. 2020;191:145-7.

61. Fox SE, Akmatbekov A, Harbert JL, et al. Pulmonary and Cardiac Pathology in Covid-19: The First Autopsy Series from New Orleans. medRxiv. 2020 Apr 10;2020.04.06.20050575.

62. Leow MK, Kwek DS, Ng AW, et al. Hypocortisolism in survivors of severe acute respiratory syndrome (SARS). Clin Endocrinol (Oxf). 2005 Aug;63(2):197-202.

63. Pal R, Banerjee M. COVID-19 and the endocrine system: exploring the unexplored. J Endocrinol Invest. 2020 May 2;1-5.

64. Wheatland R. Molecular mimicry of ACTH in SARS implications for corticosteroid treatment and prophylaxis. Med Hypotheses. 2004;63(5):855-62.
65. Xu J, Zhao S, Teng T, et al. Systematic Comparison of Two Animal-to-Human Transmitted Human Coronaviruses: SARSCoV-2 and SARS-CoV. Viruses. 2020 22;12(2).

66. Somasundaram NP, Ranathunga I, Ratnasamy V, et al. The Impact of SARS-Cov-2 Virus Infection on the Endocrine System. J Endocr Soc [Internet]. 2020 Aug 1 [cited 2020 Sep 2];4(8). Available from: https://academic.oup.com/jes/article/4/8/ bvaa082/5863314

67. Jonklaas J, Bianco AC, Bauer AJ, et al. Guidelines for the Treatment of Hypothyroidism: Prepared by the American Thyroid Association Task Force on Thyroid Hormone Replacement. Thyroid. 2014 Sep 29;24(12):1670-751.

68. Wei L, Sun S, Xu C, et al. Pathology of the thyroid in severe acute respiratory syndrome. Hum Pathol. 2007 Jan;38(1):95-102.

69. F L, X L, W Z, et al. Highly ACE2 Expression in Pancreas May Cause Pancreas Damage After SARS-CoV-2 Infection. 2020 Mar 3 [cited 2020 Oct 28]; Available from: https://europepmc.org/ article/ppr/ppr115459

70. Yang J-K, Lin S-S, Ji X-J, et al. Binding of SARS coronavirus to its receptor damages islets and causes acute diabetes. Acta Diabetol. 2010;47(3):193-9.

71. Wan J, Sun W, Li X, et al. Inflammation inhibitors were remarkably up-regulated in plasma of severe acute respiratory syndrome patients at progressive phase. Proteomics. 2006 May 9;6(9):2886-94.

72. Ma L, Xie W, Li D, et al. Effect of SARS-CoV-2 infection upon male gonadal function: A single center-based study. medRxiv. 2020 Mar 30;2020.03.21.20037267.

73. Holshue ML, DeBolt C, Lindquist $S$, et al. First Case of 2019 Novel Coronavirus in the United States. New England Journal of Medicine. 2020 Mar 5;382(10):929-36.

74. Lin L, Jiang X, Zhang Z, et al. Gastrointestinal symptoms of 95 cases with SARS-CoV-2 infection. Gut. 2020 Jun;69(6):9971001.

75. Samanta J, Dhar J, Khaliq A, et al. 2019 Novel Coronavirus Infection: Gastrointestinal Manifestations. Journal of Digestive Endoscopy. 2020 Mar;11(1):13-8.

76. Guan W, Ni Z, Hu Y, et al. Clinical Characteristics of Coronavirus Disease 2019 in China. New England Journal of Medicine. 2020 Apr 30;382(18):1708-20.

77. Leung WK, To K-F, Chan PKS, et al. Enteric involvement of severe acute respiratory syndrome-associated coronavirus infection. Gastroenterology. 2003 Oct;125(4):1011-7.

78. Pan L, Mu M, Yang P, et al. Clinical Characteristics of COVID-19 Patients With Digestive Symptoms in Hubei, China: A Descriptive, Cross-Sectional, Multicenter Study. Official journal of the American College of Gastroenterology | ACG. 2020 May;115(5):766-773.

79. Wang D, Hu B, Hu C, et al. Clinical Characteristics of 138 Hospitalized Patients With 2019 Novel Coronavirus-Infected Pneumonia in Wuhan, China. JAMA. 2020 Mar 17;323(11):1061-9.

80. HenryBM, deOliveira MHS, Benoit J, etal. Gastrointestinal symptoms associated with severity of coronavirus disease 2019 (COVID-19): a pooled analysis. Intern Emerg Med. 2020 Apr 17;1-3.

81. Zhang $H$, Kang $Z$, Gong $H$, et al. Digestive system is a potential route of COVID-19: an analysis of single-cell coexpression pattern of key proteins in viral entry process. Gut. 
2020 Jun;69(6):1010-8.

82. Xie C, Jiang L, Huang G, et al. Comparison of different samples for 2019 novel coronavirus detection by nucleic acid amplification tests. Int J Infect Dis. 2020 Apr;93:264-7.

83. Musa S. Hepatic and gastrointestinal involvement in coronavirus disease 2019 (COVID-19): What do we know till now? Arab Journal of Gastroenterology. 2020 Mar 1;21(1):3-8.

84. Xiao F, Tang $M$, Zheng $X$, et al. Evidence for Gastrointestinal Infection of SARS-CoV-2. Gastroenterology. 2020 May;158(6):1831-1833.e3.

85. Ranjbar R, Shafiee M, Hesari A, et al. The potential therapeutic use of renin-angiotensin system inhibitors in the treatment of inflammatory diseases. J Cell Physiol. 2019;234(3):2277-95.

86. Hashimoto T, Perlot T, Rehman A, et al. ACE2 links amino acid malnutrition to microbial ecology and intestinal inflammation. Nature. 2012 Jul;487(7408):477-81.

87. Fan Z, Chen L, Li J, et al. Clinical Features of COVID-19 Related Liver Damage. medRxiv. 2020 Feb 28;2020.02.26.20026971.

88. Chai $X, \mathrm{Hu}$ L, Zhang $Y$, et al. Specific ACE2 Expression in Cholangiocytes May Cause Liver Damage After 2019-nCoV Infection. bioRxiv. 2020 Feb 4;2020.02.03.931766.

89. Hoffmann $\mathrm{M}$, Kleine-Weber $\mathrm{H}$, Krüger $\mathrm{N}$, et al. The novel coronavirus 2019 (2019-nCoV) uses the SARS-coronavirus receptor ACE2 and the cellular protease TMPRSS2 for entry into target cells. bioRxiv. 2020 Jan 31;2020.01.31.929042.

90. Zhang C, Shi L, Wang F-S. Liver injury in COVID-19: management and challenges. Lancet Gastroenterol Hepatol. 2020 May;5(5):428-30.

91. Gu J, Han B, Wang J. COVID-19: Gastrointestinal Manifestations and Potential Fecal-Oral Transmission. Gastroenterology. 2020;158(6):1518-9.

92. Ye M, Wysocki J, William J, et al. Glomerular localization and expression of Angiotensin-converting enzyme 2 and Angiotensin-converting enzyme: implications for albuminuria in diabetes. J Am Soc Nephrol. 2006 Nov;17(11):3067-75.

93. Sun J, Zhu A, Li H, et al. Isolation of infectious SARSCoV-2 from urine of a COVID-19 patient. Emerging Microbes \& Infections. 2020 Jan 1;9(1):991-3.

94. Hirsch JS, Ng JH, Ross DW, et al. Acute kidney injury in patients hospitalized with COVID-19. Kidney International. 2020 Jul 1;98(1):209-18.

95. Benedetti C, Waldman M, Zaza G, et al. COVID-19 and the Kidneys: An Update. Front Med [Internet]. 2020 [cited 2020 Oct 28];7. Available from: https://www.frontiersin.org/ articles/10.3389/fmed.2020.00423/full

96. Su H, Yang M, Wan C, et al. Renal histopathological analysis of 26 postmortem findings of patients with COVID-19 in China. Kidney International. 2020 Jul 1;98(1):219-27.

97. Volunteers A-2019-nCoV, Li Z, Wu M, et al. Caution on Kidney Dysfunctions of COVID-19 Patients. medRxiv. 2020 Mar 27;2020.02.08.20021212.

98. Wu H, Uchimura K, Donnelly EL, et al. Comparative Analysis and Refinement of Human PSC-Derived Kidney Organoid Differentiation with Single-Cell Transcriptomics. Cell Stem Cell. 2018 Dec 6;23(6):869-881.e8.
99. Pan X-W, Xu D, Zhang H, et al. Identification of a potential mechanism of acute kidney injury during the COVID-19 outbreak: a study based on single-cell transcriptome analysis. Intensive Care Med. 2020;46(6):1114-6.

100. Bourgonje AR, Abdulle AE, Timens W, et al. Angiotensinconverting enzyme 2 (ACE2), SARS-CoV-2 and the pathophysiology of coronavirus disease 2019 (COVID-19). The Journal of Pathology. 2020;251(3):228-48.

101. Gu H, Xie Z, Li T, et al. Angiotensin-converting enzyme 2 inhibits lung injury induced by respiratory syncytial virus. Sci Rep [Internet]. 2016 Jan 27 [cited 2020 Sep 1];6. Available from: https:// www.ncbi.nlm.nih.gov/pmc/articles/PMC4728398/

102. Zheng Y-Y, Ma Y-T, Zhang J-Y, et al. COVID-19 and the cardiovascular system. Nature Reviews Cardiology. 2020 May;17(5):259-60.

103. Gurwitz D. Angiotensin receptor blockers as tentative SARS-CoV-2 therapeutics. Drug Development Research. 2020;81(5):537-40. 